\title{
Glioma-like proliferation in a cortical hamartoma of tuberous sclerosis complex
}

\author{
Ekkehard Hewer $\cdot$ Luigi Mariani · Istvan Vajtai
}

Received: 22 January 2014/ Accepted: 23 March 2014/Published online: 11 April 2014

(C) The Japan Society of Brain Tumor Pathology 2014

Sir,

Cortical glioneuronal hamartomas (tubers) are a major diagnostic criterion of the tuberous sclerosis complex (TSC) and among its most prevalent CNS manifestations [1]. In 2008, Fischer et al. [2] reported on a peculiar type of neuroepithelial proliferation they observed in resected cortical tubers in 5 out of 40 patients with TSC. These "gliomatosis cerebri-like" cells exhibited a rudimentary astrocytic phenotype, a broad range of proliferation rates (MIB-1/Ki67 labeling indices: 1-21\%) along with variable immunoreactivity for glial fibrillary acidic protein (GFAP) and phosphorylated ribosomal protein S6 (pS6; a surrogate marker of mTOR pathway activation), while lacking neuronal markers. Post-operative follow-up for up to 34 months did not show any evidence of progression of these apparently non-static lesions. In sum, Fischer et al. interpreted their findings as "suggestive, but not diagnostic of a neoplasm" and discussed similarities to a previously reported type of "isomorphic gliomas", associated with long-term epilepsy [3]. Here we report our findings in a pertinent case, which to our knowledge represents the first independent confirmation of this phenomenon.

E. Hewer $(\bowtie) \cdot$ I. Vajtai

Institute of Pathology, University of Bern, Murtenstrasse 31, 3010 Bern, Switzerland

e-mail: ekkehard.hewer@pathology.unibe.ch

\section{Mariani}

Department of Neurosurgery, University Hospital Basel, Basel, Switzerland

Present Address:

I. Vajtai

Institute of Pathology "Laenggasse", Bern, Switzerland
The 31-year-old female TSC patient underwent resection of a right fronto-parietal cortical lesion for treatment of pharmacoresistant epilepsy. The focus had been identified by magnetic resonance imaging (MRI) and electrocorticography. Histologically, the resection specimen revealed typical features of a cortical tuber, which were, however, accompanied by a proliferation of mildly atypical cells of astrocytic morphology resembling a diffusely infiltrating low-grade glioma on hematoxylin-eosin staining (Fig. 1a-d). The critical population was variably immunoreactive for NeuN and GFAP (Fig. 1e-f). The MIB-1 labeling index focally exceeded $5 \%$ (Fig. 1g). Both tuberal balloon cells and the glioma-like proliferation stained for pS6 (Fig. 1h). Rare cells were weakly immunoreactive for $\mathrm{p} 53$ (not shown), consistent with proliferation-associated p53 expression, while there was no positivity for R132H-mutant IDH1 (not shown) and nuclear ATRX immunoreactivity was retained (Fig. 1i).

At present, 29 months after resection, there is no evidence of recurrent disease. The resection, however, did not result in satisfactory control of seizures, so that a vagal nerve stimulator was implanted subsequently.

Our observations replicate most of the salient features recorded in the series by Fischer et al., and thereby confirm the occurrence of a glioma-like proliferation in a subset of cortical tubers in TSC patients [2]. In addition, we found immunohistochemical alterations common in diffuse astrocytomas (p53 accumulation, immunoreactivity for R132H-mutant IDH1, ATRX loss) to be absent $[4,5]$. The pattern of pS6 immunoreactivity is consistent with these proliferations being part of the tuberous sclerosis pathology rather than an independent (neoplastic or reactive) process.

In sum, we suggest that this glioma-like proliferation may represent a unique mimic of diffusely infiltrating gliomas, that adds to the list of pseudoneoplastic lesions of 

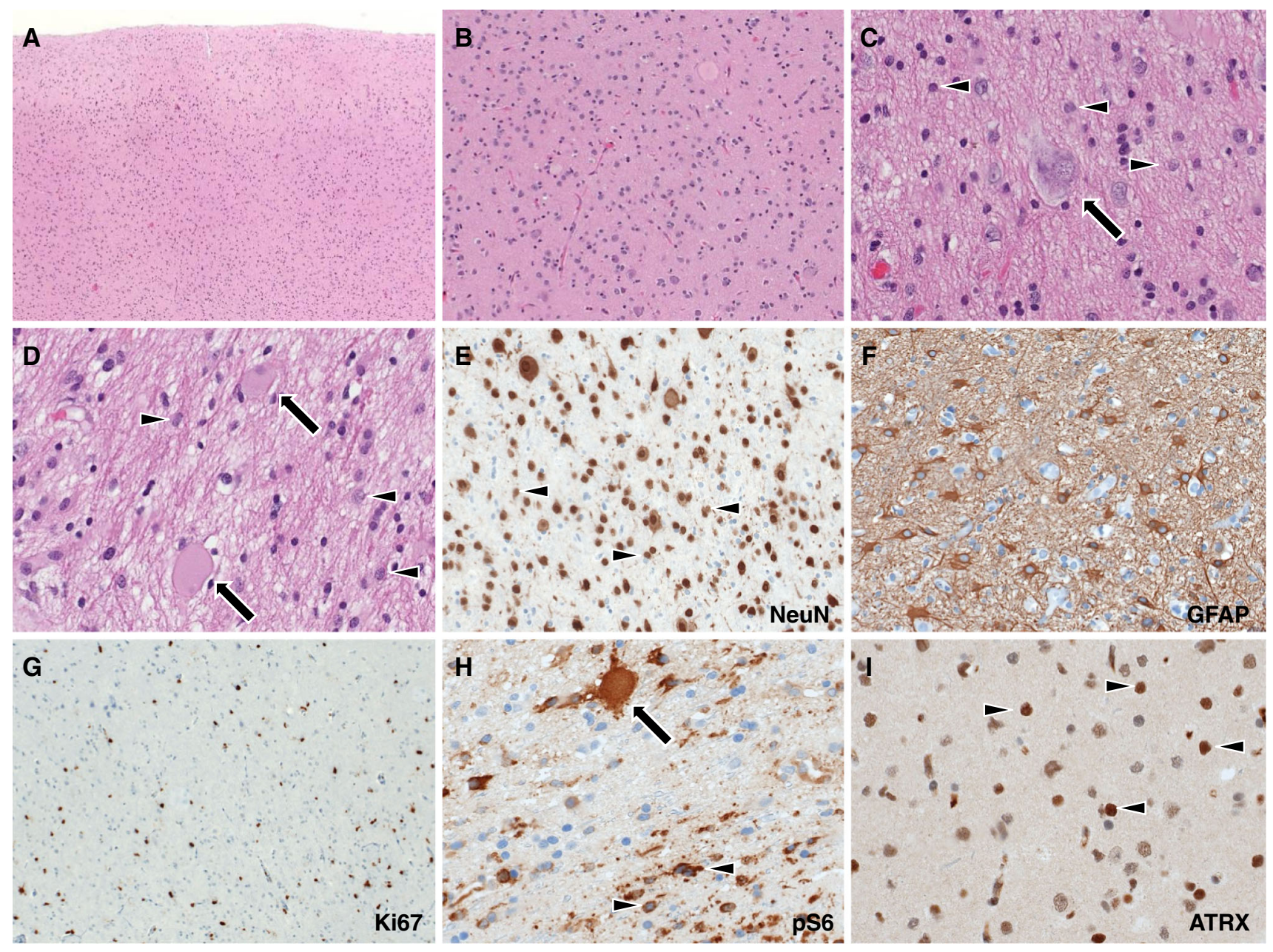

Fig. 1 Low-power magnification of the resection specimen showed a hypercellular and disorganized cortex (a). Hypercellularity of the cortex was due to a population of cells resembling those of a diffusely infiltrating low-grade glioma (b), which were identified (arrowheads in $\mathbf{c}$ and $\mathbf{d}$ ) in addition to the cellular constituents of a cortical tuber, i.e. dysmorphic neurons (arrow in c) and ballooned cells (arrows in d). The critical cells were mostly positive for neuronal markers, including NeuN (arrowheads in e). Note that while lack of polarity or layered distribution easily identifies glioma-like infiltrate as a population, unambiguous singling-out of individual lesional cells is

the central nervous system [6]. A practical relevance of this phenomenon relates to the potential for confusion with a conventional diffuse astrocytoma. In particular, the elevated proliferative activity observed in some of the lesions (including the present one) might-in spite of absent mitotic activity-lead to an erroneous diagnosis of anaplastic astrocytoma and unwarranted adjuvant therapy.

Nevertheless, post-operative follow-up should be recommended in this setting given that follow-up periods were limited in both the original series of cases and the present case, so that a possibility of late recurrences remains. Furthermore, pS6 expression indicates mTOR pathway activation in the glioma-like proliferation, but of course not forthcoming. Expression of glial fibrillary acidic protein (GFAP) was felt to be rather arbitrarily either present or absent in the lesional cells irrespective of their conventional cytologic appearance (f). Proliferation index (MIB-1/Ki67) exceeded $5 \%$ in some areas and focally reached $10 \%(\mathrm{~g})$. The infiltrative-appearing population of cells was immunoreactive for phosphorylated ribosomal protein S6 (arrowheads in $\mathbf{h}$ ), a surrogate of mTOR pathway activation, as were dysmorphic neurons and balloon cells (arrow in h). Normal ATRX immunoreactivity was retained in lesional cells (arrowheads in i)

does not per se prove its non-neoplastic nature-in particular, since the mTOR pathway is involved in the pathogenesis of various types of sporadic gliomas [7, 8]. Finally, true gliomas have been repeatedly reported in TSC [9-12], some of which have been co-localized with cortical tubers [12] or been interpreted as malignant progression of a TSC-associated lesion [11] (in this particular case a subependymal giant cell astrocytoma).

However, the above considerations ex negativo do not answer, what the nature of these glioma-like proliferations actually is. Remarkably, many of the lesional cells in the series by Fischer et al. did not exhibit an unambiguous astrocytic immunophenotype (GFAP)—a finding also 
replicated in the present case. Conversely, we detected NeuN expression in a subset of otherwise nondescript cells within the proliferation. Such indeterminate phenotype is common across the spectrum of glioneuronal lesions [13]. We are tempted to speculate that this "glioma-like" proliferation possibly reflects a transitory state of postnatal tuber development. Indeed, recent studies suggest tubers to be dynamic lesions despite their lacking propensity for growth $[14,15]$. Along this line of thought, tuber-associated glioma-like proliferation may attract particular interest in the context of current attempts to pharmacologically interfere with formation of TSC-associated CNS lesions $[16,17]$.

Conflict of interest The authors declare that they have no conflict of interest.

\section{References}

1. Lopes MBS, Wiestler OD, Stemmer-Rachamimov AO, Sharma MC (2007) Tuberous sclerosis complex and subependymal giant cell astrocytoma. In: Louis DN, Ohgaki H, Wiestler OD, Cavenee WK (eds) WHO classification of tumours of the central nervous system. IARC, Lyon, pp 218-221

2. Fischer I, Cunliffe C, Bollo RJ, Weiner HL, Devinsky O, RuizTachiquin ME, Venuto T, Pearlman A, Chiriboga L, Schneider RJ, Ostrer H, Miller DC (2008) Glioma-like proliferation within tissues excised as tubers in patients with tuberous sclerosis complex. Acta Neuropathol 116:67-77

3. Blümcke I, Luyken C, Urbach H, Schramm J, Wiestler OD (2004) An isomorphic subtype of long-term epilepsy-associated astrocytomas associated with benign prognosis. Acta Neuropathol 107:381-388

4. Paulus W (2009) GFAP, Ki67 and IDH1: perhaps the golden triad of glioma immunohistochemistry. Acta Neuropathol 118:603-604

5. Liu XY, Gerges N, Korshunov A, Sabha N, Khuong-Quang DA, Fontebasso AM, Fleming A, Hadjadj D, Schwartzentruber J, Majewski J, Dong Z, Siegel P, Albrecht S, Croul S, Jones DT, Kool M, Tonjes M, Reifenberger G, Faury D, Zadeh G, Pfister S,
Jabado N (2012) Frequent ATRX mutations and loss of expression in adult diffuse astrocytic tumors carrying IDH1/IDH2 and TP53 mutations. Acta Neuropathol 124:615-625

6. Cunliffe CH, Fischer I, Monoky D, Law M, Revercomb C, Elrich S, Kopp MJ, Zagzag D (2009) Intracranial lesions mimicking neoplasms. Arch Pathol Lab Med 133:101-123

7. Annovazzi L, Mellai M, Caldera V, Valente G, Tessitore L, Schiffer D (2009) mTOR, S6 and AKT expression in relation to proliferation and apoptosis/autophagy in glioma. Anticancer Res 29:3087-3094

8. Mueller S, Phillips J, Onar-Thomas A, Romero E, Zheng S, Wiencke JK, McBride SM, Cowdrey C, Prados MD, Weiss WA, Berger MS, Gupta N, Haas-Kogan DA (2012) PTEN promoter methylation and activation of the PI3K/Akt/mTOR pathway in pediatric gliomas and influence on clinical outcome. Neuro Oncol 14:1146-1152

9. Al-Saleem T, Wessner LL, Scheithauer BW, Patterson K, Roach ES, Dreyer SJ, Fujikawa K, Bjornsson J, Bernstein J, Henske EP (1998) Malignant tumors of the kidney, brain, and soft tissues in children and young adults with the tuberous sclerosis complex. Cancer 83:2208-2216

10. Padmalatha C, Harruff RC, Ganick D, Hafez GB (1980) Glioblastoma multiforme with tuberous sclerosis. Report of a case. Arch Pathol Lab Med 104:649-650

11. Stenzel W, Franitza M, Becker AJ, Montesinos-Rongen M, Lohr M, Lee JY, Rohn G, Miletic H, Deckert M (2007) A 30-year-old patient with tuberous sclerosis. Brain Pathol 17:333-334

12. Eren S, Polat P, Erman Z (2002) An unusual tuberous sclerosis case presenting with fibrillary astrocytoma. Pediatr Neurosurg 37:118-121

13. Thom M, Blumcke I, Aronica E (2012) Long-term epilepsyassociated tumors. Brain Pathol 22:350-379

14. Crino PB (2004) Molecular pathogenesis of tuber formation in tuberous sclerosis complex. J Child Neurol 19:716-725

15. Crino PB (2013) Evolving neurobiology of tuberous sclerosis complex. Acta Neuropathol 125:317-332

16. Kotulska K, Borkowska J, Jozwiak S (2013) Possible prevention of tuberous sclerosis complex lesions. Pediatrics 132:e239-e242

17. Tillema JM, Leach JL, Krueger DA, Franz DN (2012) Everolimus alters white matter diffusion in tuberous sclerosis complex. Neurology 78:526-531 